\title{
DEMOGRAPHIC DIFFERENTIALS IN THE DEMAND FOR ALCOHOL AND ILLICIT DRUGS
}

Henry Saffer

Frank Chaloupka

Working Paper 6432 
NBER WORKING PAPER SERIES

\title{
DEMOGRAPHIC DIFFERENTIALS IN THE DEMAND FOR ALCOHOL AND ILLICIT DRUGS
}

\author{
Henry Saffer \\ Frank Chaloupka
}

Working Paper 6432

http://www.nber.org/papers/w6432

\author{
NATIONAL BUREAU OF ECONOMIC RESEARCH \\ 1050 Massachusetts Avenue \\ Cambridge, MA 02138 \\ February 1998
}

This project was supported by grant no. R01-AA-09435 from the National Institute on Alcohol Abuse and Alcoholism to the National Bureau of Economic Research. The authors would like to thank Michael Grossman for helpful comments and Esel Yazici for programming assistance. This paper has been prepared for the National Bureau of Economic Research conference, The Economic Analysis of Substance Use and Abuse: An Integration of Econometric and Behavioral Economic Research, March 27 and 28, 1997, Cambridge, Massachusetts. Any opinions expressed are those of the authors and not those of the National Bureau of Economic Research.

(C) 1998 by Henry Saffer and Frank Chaloupka. All rights reserved. Short sections of text, not to exceed two paragraphs, may be quoted without explicit permission provided that full credit, including (C) notice, is given to the source. 
Demographic Differentials in the Demand

for Alcohol and Illicit Drugs

Henry Saffer and Frank Chaloupka

NBER Working Paper No. 6432

February 1998

\section{ABSTRACT}

The purpose of this paper is to estimate demographic differentials in alcohol and illicit drug use, participation, own price effects and cross price effects. This paper uses a data set of over 49,000 individuals from the National Household Survey of Drug Abuse and links drug and alcohol prices and policies to the individual records. The size of this data set makes it possible to estimate use, participation and demand curves for specific demographic groups. Public policies designed to reduce substance abuse have been oriented towards increasing the price of alcohol and illicit drugs. Little, however, is known about the relative responsiveness of various demographic groups to these policies. The data show that racial and ethnic minorities consume more cocaine, but consume less or equal amounts of alcohol, marijuana and heroin than the total population. The results also show a consistent pattern of negative own price effects for alcohol and illicit drugs and complimentarity between alcohol and illicit drugs. The own price effects did not differ substantially between demographic groups suggesting that price policies have a similar effect on all demographic groups. The pattern of complimentarity between alcohol and illicit drugs suggests that alcohol taxes also reduce drug use.

Henry Saffer

National Bureau of Economic Research

50 East 42nd Street, 17th Floor

New York, NY 10017-5405

hsaffer@email.gc.cuny.edu
Frank Chaloupka

Department of Economics (M/C 144)

University of Illinois at Chicago

601 South Morgan

Chicago, IL 60607-7121

and NBER

fjc@uic.edu 


\section{Introduction}

For a number of years, government at the Federal, state, and local levels and various private groups have engaged in a campaign to discourage alcohol and illicit drug use. These efforts have been motivated by an increasing awareness of the consequences of alcohol and drug abuse. Alcohol and drug abuse imposes significant costs on society and on the individual users. These costs include alcohol and drug related health problems, employment problems and crime Health costs from alcohol and drug abuse are the result of fatal and non-fatal accidents, especially on the highway and at work, liver cirrhosis, heart disease, various cancers and accidental overdoses. In addition, there are costs due to poor birth outcomes and the physical, and emotional damage caused to children by alcohol and drug abusing parents. Employment costs from alcohol and drug abuse are lost income due to reduced productivity, increased unemployment and absenteeism and changes in career choice. Crime costs from alcohol and drug abuse are due to psychological effects on users, the need to generate income to buy drugs and to lesser extent to buy alcohol, and result from the extra-legal nature of illicit drugs transactions.

Although the anti-alcohol and anti-drug campaigns have produced results, significant problems remain. One part of the campaign has been the introduction or strengthening of policies which directly or indirectly increase the costs of alcohol and drug abuse. Policies which increase the cost of alcohol abuse include increases in alcohol taxes and increased sanctions against drunk driving. Policies which are intended to increase the cost of drugs include interdiction of drug shipments, eradication of drug crops in the field, and drug related criminal justice efforts. The assumption is that these policies increase the price of alcohol and drugs and thus reduce use of these substances. One shortcoming of these campaigns has been the lack of emphasis on potential demographic differences in the response to public policies. If one or more demographic groups are relatively unresponsive to price, then alternative policies might be appropriate. Estimation of 
the effect of price, by demographic group, would be helpful in designing the mix of strategies that will be most successful in reducing overall alcohol and drug abuse.

The purpose of this paper is to estimate, for specific demographic groups, differentials in use, participation and differentials in the effects of alcohol and drug prices and cross prices on alcohol and drug use. There are few prior empirical studies of this nature because of insufficient data. This paper employs a data set of over 49,000 individuals derived from the National Household Survey of Drug Abuse (NHSDA) which has been augmented with alcohol and drug price data. Two novel features of this paper are the estimation of drug and demographic specific demand curves with drug price data and the estimation alcohol price effects with county level alcohol prices and data from the NHDSA. The results for eight specific demographic groups are presented in this paper. Estimation by specific demographic group allows for demographic specific effects of all the included variables without the need to include potentially problematic set of interaction terms. It is also important to test for cross price effects since these effects may enhance or dilute the effects of price policies. If a pair of substances are substitutes then increasing the price of one will induce more use of the other substance. Alternatively, if the substances are compliments then an increase in the price of one will reduce use of both. Estimates of alcohol and drug price and cross price effects by demographic group are important since demographic groups may respond differently to alcohol and drug control policies.

\section{Prior Studies}

The empirical literature on the effects of alcohol prices is considerably larger than the empirical literature on the effects of drug prices. This difference is due to the greater availability of alcohol price data. These alcohol and drug studies generally include a number of demographic measures as independent variables which provides some insight into demographic differentials in 
drug and alcohol use. A few studies specifically examine cross price effects between alcohol and marijuana and a few studies specifically estimate the effects of price on alcohol and drug use with data sets limited to youth or women.

\subsection{Alcohol Studies}

The empirical literature provides considerable evidence which shows that increasing the price of alcoholic beverages decreases alcohol use. Leung and Phelps (1993) review of 21 of these studies. Alcohol demand studies generally estimate price elasticities for beer, wine and spirits separately. Most studies employ aggregate data but a few use individual data. Studies using aggregate data find price elasticities for beer from about -.2 to about -1.0 , for wine from about -.3 to about -1.8 and for spirits from about -.3 to about -1.8 . Studies using individual data estimate price elasticities for beer from about -.5 to about -3.0 , for wine at about -.5 and for spirits from about -.5 to about -4.0 . A study by Kendell, de Roumanie, and Ritson (1983) estimates price elasticities of total alcohol for men at -1.95 and for women at -2.19 . Also a study by Grossman, Coate and Arluck (1987) estimates beer price elasticities for youth at -3.05 and spirits price elasticities for youth at -3.83 . Kenkel (1993) estimates alcohol price elasticities for men at -.48 and for women at -1.07 . It appears that women and youth may have somewhat more elastic alcohol demand than the population in general.

Two alcohol studies with individual data also include a number of right hand side demographic variables. Heien and Pompelli (1988) find that being black increases beer and spirits consumption, but decreases wine consumption and being single increases alcohol consumption. Kenkel (1993) finds that being black, Hispanic, married, or a divorced women has a negative effect on heavy drinking. Kenkel finds that being a divorced male increases heavy drinking.

\subsection{Drug Studies}

There are a few prior empirical studies of the effects of drug prices on drug use. There are 
no studies which use marijuana price but several that use marijuana decriminalization as a measure of full price. Saffer and Chaloupka (1995) examine the effects of marijuana decriminalization, heroin prices and cocaine prices on the use of these three drugs, respectively. They find that marijuana decriminalization increases the probability of marijuana participation by about 4 to 6 percent. The price elasticity for heroin is estimated at about -1.80 to -1.60 and for cocaine at about -1.10 to -.72 . A study by van Ours (1995) uses data on opium in Indonesia during the Dutch colonial period. He finds a price elasticity of -7 to -1.0 for use and -.3 to -.4 for participation. DiNardo (1993) studies the effect of cocaine price on cocaine use by high school seniors. He uses a state aggregated version of the Monitoring the Future (MTF) data set with drug prices from the Drug Enforcement Agency. He finds no effect of price on cocaine use. A study by Silverman and Spruill (1977) uses a pooled cross-sectional time-series data set on 41 neighborhoods of Detroit from November 1970 through July 1973. They find a price elasticity for heroin use in Detroit of about -.26 . Silverman and Spruill (1977) also find that property crime rates are positively and significantly affected by the price of heroin while non-property crime rates are not. Brown and Silverman (1974) use a time series on various crime rates in New York City to look at the impact of heroin prices on crime rates. They find that reductions in the price of heroin lead to a fall in property crimes but that prices have no impact on other crimes. The results from the crime studies suggest an inelastic demand for heroin. Nisbit and Vakil (1972) use data collected from interviews with UCLA students to estimate the demand for marijuana. They estimate the price elasticity of marijuana at -.7 to -1.0 .

There are a few additional studies which focus on the effect of marijuana decriminalization on marijuana participation. Marijuana decriminalization is a law which reduces the penalties for possession of a small amount of marijuana. Marijuana decriminalization thus has the effect of reducing the full price of marijuana use. Pacula (1994) used the National Longitudinal Survey of 
Youth (NLSY) to study the relationship between marijuana and alcohol. She included a variable measuring decriminalization but found no effect on marijuana use. Thies and Register (1993) studied the effect of marijuana decriminalization on use. They also used the NLSY and also concluded that decriminalization had no effect on use. DiNardo and Lemieux (1992) studied the relationship between marijuana and alcohol. They used the MTF surveys and included a variable measuring marijuana decriminalization. They too found that decriminalization had no effect on marijuana participation. Johnston, O'Malley and Bachman (1981) studied the effect of marijuana decriminalization using the MTF surveys of high school seniors. They concluded that decriminalization had no effect on marijuana use. All of these studies are based on samples of young people whose behavior may not be representative of the overall population.

Model (1992) studied the effect of marijuana decriminalization on crime rates using state aggregate data from the Uniform Crime Reports. She finds that decriminalization had a significant positive effect on property crimes and a significant negative effect on violent crimes. Model (1993) also studied the effect of decriminalization on hospital emergency room drug episodes. She used data from the Drug Abuse Warning Network and found that decriminalization increases marijuana related emergency room visits but decreased all other emergency room visits.

Several drug studies include demographic variables as independent variables. Sickles and Taubman (1991) find that Blacks, Hispanics and men are more likely to consume illegal drugs. They also find that age, education and religious participation has a negative effect on illicit drug use. However, DiNardo and Lemieux (1992) and Pacula (1994) find that minorities consume less or the same levels of illegal drugs as whites. Theis and Register (1993) find that marriage has a negative effect on drug use.

\subsection{Studies With Cross Price Effects Between Alcohol And Illicit Drugs}

A summary of the biomedical literature in NIAAA (1993) suggests that alcohol use and 
illicit drug use may be mutually reinforcing. That is, the use of two drugs taken together produces an effect greater than the sum of the effects of each drug taken individually. This suggests complimentary in the class of demand curves which assume a constant marginal utility of income. ${ }^{1}$ There are four econometric studies of cross price effects between alcohol and marijuana for youth. Three of these studies find some evidence of substitution and the other finds evidence of complimentary.

DiNardo and Lemieux (1992) studied the relationship between marijuana and alcohol with the MTF surveys. They included variables for marijuana decriminalization, the drinking age and alcohol price. They found that decriminalization had a significant negative effect on alcohol participation, although no effect on marijuana participation. They also found that the drinking age had a significant positive effect on marijuana participation and a negative effect on alcohol participation. They also found that the price of alcohol had no effect on marijuana participation and no effect on alcohol participation. The cross price effects suggest substitution between alcohol and marijuana for youth. This evidence would be more compelling if there were more significant own price effects.

Thies and Register (1993) studied the effect of marijuana decriminalization on marijuana, alcohol and cocaine participation using the NLSY. They found that decriminalization had a positive effect on alcohol and cocaine participation, no effect on heavy alcohol participation and no effect on marijuana participation. This suggests that alcohol and cocaine are compliments with marijuana. Again, this evidence would be more compelling if there were more significant own price effects.

Chaloupka and Laixuthai (1994) used the 1982 and 1989 MTF surveys to study the relationship between alcohol and marijuana. They included variables measuring marijuana price,

\footnotetext{
${ }^{1}$ This assumption was first proposed by Ragnar Frisch (1932) and has been most recently employed in rational addiction models.
} 
decriminalization and beer taxes. They found that drinking participation and heavy drinking are positively related to the price of marijuana, negatively related to decriminalization and negatively related to beer taxes. These results suggest that alcohol and marijuana are substitutes.

Pacula (1994) used the National Longitudinal Survey of Youth (NLSY) to study the relationship between marijuana and alcohol. She included variables measuring decriminalization, beer taxes, and legal drinking age. She found that beer taxes reduced marijuana participation and alcohol participation. She also found that decriminalization reduced alcohol participation but has no effect on marijuana participation. The legal drinking age was never significant. This evidence suggests that alcohol and marijuana are substitutes.

\section{Data Set}

\subsection{Introduction}

The empirical models estimated in this paper are demand curves. The basis of these empirical demand curves is the same theoretical demand model that is used for other goods. Theoretical drug demand curves are derived in the usual fashion by maximizing individual utility subject to a budget constraint consisting of the full price, other prices and income. The derived demand curves show that drug consumption is negatively related to the full price and related, without a priori sign, to income and taste. The data used to estimate these demand curves comes from a pool of the 1988, 1990 and 1991 National Household Surveys on Drug Abuse (NHSDA). ${ }^{2}$ The pooled data set consists of 49,802 observations, which allows for selection of relatively large demographic specific samples. County level alcohol prices, state level marijuana decriminalization laws and state level drug prices have been appended to the individual records. ${ }^{3}$

\footnotetext{
- The 1988,1990 and 1991 surveys are very similar except for size. The 1991 survey is over three times as large as the 1988 and 1990 surveys. The 1991 survey is larger, in part, because six PSUs were oversampled. Each survey also oversamples persons aged 12-17, Hispanics and African Americans.

${ }^{3}$ We are indebted to the Office of Applied Studies, SAMHSA, for merging the county and state level data to the individual records in the NHSDA. With the exception of one PSU in 1990 and six PSUs in 1991, no locational identifiers are available due to confidentiality issues.
} 
In addition to the full sample, seven demographic specific samples were selected from the pooled NHSDA data set. The seven groups are: 1) White-Male-non-Hispanic, 2) Black, 3) Asian, 4) Native American, 5) Women, 6) Youth and 7) Hispanic. The survey defines individuals as identified with one of four mutually exclusive and exhaustive race categories. These race groups are: 1) White, 2) Black, 3) Asian or Pacific Islander, and 4) Native American or Alaskan Native. The survey also defines people as Hispanic or Nonhispanic with four categories of Hispanic included: 1) Puerto Rican, 2) Mexican, 3) Cuban and 4) other Hispanic. ${ }^{4}$ The White-MaleNonhispanic group was selected as a group to use for comparison with other groups. The regressions using the Black, Native American and Asian samples include a Hispanic variable to control for possible differences due to Hispanic ethnicity. The regressions for Women and Youth include variables for race and Hispanic ethnicity. The Hispanic regressions include variables for Cuban, Puerto Rican, Mexican, with the 'other Hispanic' as the omitted category. For ease of comparisons with other data sets regressions based on all the data are also presented. These regressions include variables for Black, Asian, Native American, Women, Youth and Hispanic. A summary of the variable definitions and means are included in table 1 . The means presented in this table are weighted so that they are comparable to a random sample of the US. ${ }^{5}$

\subsection{Dependent Variables}

The dependent variables in this study are a continuous measure of alcohol participation and dichotomous measures of marijuana, cocaine and heroin participation. The alcohol participation variable measures the number of days in the past 30 days that the individual had consumed alcohol. The drug participation variables are equal to one if the individual reports that they had used the substance during the past year.

\footnotetext{
${ }^{4}$ An individual can be in any one of the four racial groups and also be Hispanic or Nonhispanic.

${ }^{5}$ The data are weighted using the analysis weight variable in each survey. The individual data is multiplied by the weight variable and then divided by the sum of the weight variable. The means for combined data are computed as a weighted average of weighted means for the three surveys. The weights are defined as the sample size divided by
} 


\subsection{Price data}

The price of alcohol consists of the prices of beer, wine, and distilled spirits. Data on the prices come from the American Chamber of Commerce Research Association's quarterly InterCity Cost of Living Index $(1988,1990,1991)$. This index contains prices, inclusive of taxes, for over 250 cities each quarter, and was used to construct county level prices. This data was merged with the NHSDA on a PSU level. ${ }^{6}$ A single alcohol price variable, the price of one pure liter of alcohol, was created from the beer, wine and spirits prices. This computation was done by first computing the price per liter for each beverage. The price of beer is reported for a six pack. The price was divided by 2.13 which is the number of liters in a six pack. Since the price of wine is reported for a 1.5 liter bottle the wine price was divided by this number. Spirits prices are reported for a liter bottle. Next, the these liter prices were divided by the percent alcohol in each beverage (.04 for beer, .11 for wine and .41 for spirits). A weighted average price of pure alcohol can now be computed. The weights are the share of pure alcohol consumption represented by each beveragc. These weights are .569 for beer, .113 for wine and .318 for spirits. These weight data come from the Brewer's Association of Canada International Survey. Prices were adjusted to their real value in $1982-1984$ dollars.

Prices for cocaine and heroin come from the US Department of Justice, Drug Enforcement Agency's STRIDE data set. ${ }^{7}$ Drug Enforcement Administration agents and police narcotics officers purchase illicit drugs regularly. The price, purity, weight and other information are recorded in the STRIDE data set. One reason these price data are collected is so that DEA

the total size of the three samples.

"There was no ACCRA data available for Washington DC, so an average price from urban Virginia and urban Maryland was used.

'There are price data for marijuana from the Drug Enforcement Agency's Domestic Cities Report. These prices are for retail and wholesale commercial grade marijuana for 19 cities in 16 states. Use of this data required a significant reduction in the number of observations used in the analysis. A number of alternative estimates of the price of marijuana were made with this data. The resulting price variables were inconsistent with all other price data in the data set and resulted in unstable coefficients when used in a series of alternative demand specifications. For these reasons. these marijuana price data were not used. 
agents will know how much to offer when negotiating to buy from drug dealers. The price data are fairly accurate since inaccurate data would endanger these agents. The STRIDE data set provided by the DEA to the NBER contains cocaine and heroin data from 1977 through 1988 and 1991 for approximately 144 cities or towns. This data set has over 23,000 cocaine price observations and over 15,000 heroin price observations.

The procedure described in more detail in Saffer and Chaloupka (1995) was followed to estimate heroin and cocaine prices. Briefly, to estimate drug prices the log of purity was regressed on log of weight, city dummies and time dummies. This regression was used to project an estimated purity variable for all observations. Next, the log of price was regressed on the log of the weight times the estimated purity, city dummies and time dummies. ${ }^{8}$ This regression was performed by entering log weight and log estimated purity as separate variables and constraining their coefficients to be identical. Setting weight at 1 unit and purity at 100 percent makes the log of these values zero. The estimated coefficients of the city dummies and time dummies were then used to predict a price for every city-time combination. The projected price is the price of one unit of 100 percent pure drug. The antilog was then computed and the local level prices were aggregated to the state level. This aggregation was computed as a weighted average of all the represented cities in the state. The population weights for each city were computed by dividing the city population by the total population of all represented cities in the state. The population data come from the City and County Databook (1993).

There are two issues regarding the price data that are important. The first issue is the exogeneity of price. Alcohol prices vary because taxes, transportation costs and local cost conditions. These variables are independent of local alcohol demand variations making the price of alcohol exogenous. If drug supply is not horizontal, then price and quantity would be

\footnotetext{
${ }^{8}$ This is a reduced form price equation from a supply and demand model. The city and time dummies are proxies for unobserved city and time specific factors.
} 
endogenous. However, since the predicted price variable used in the regressions comes from a reduced form model it is uncorrelated with the error term in the demand equation. The second issue is measurement error. Merging individual level drug use data with state level drug prices introduces a potential for measurement error due to matching. Any measurement error created by the matching problem is probably small since, in each state, most drug users are in the larger urban areas and, for each state, the drug price data comes mostly from the larger urban areas. If there is any matching measurement error in the price data, but it is uncorrelated with the included regressors, and the equation crror term, then no bias will be introduced.

The full price of marijuana is, in part, reflected by the decriminalization law. This law specifically eliminates criminal sanctions for possession of small amounts of marijuana. Decriminalization of marijuana eliminates possible imprisonment for most first offense possession violations. Oregon, in 1973, was the first state to decriminalize marijuana. By 1978, 10 other states had followed, substantially reducing the penalties associated with marijuana possession. Decriminalization, by lowering the penalties associated with marijuana use, is expected to increase marijuana demand.

\subsection{Other Independent Variables}

Total personal income is defined as income from all sources including wages, selfemployment, social security, public assistance, child support and other pension income. Income is a continuous variable measured in dollars and has been adjusted to its real value in 1982-1983 dollars. If alcohol and drugs are normal goods, increased income will lead to increased consumption. However, since health is a normal good, increased income may reduce the consumption of alcohol and drugs. The net effect of an increase in income on demand is, thus, without a priori prediction.

A group of dichotomous demographic variables are also included in certain regressions 
These are age, race, ethnicity, gender and marital status. A youth variable has been defined as equal to one if the individual is between 12 and 20. Three dichotomous race variables are defined: Black, Asian, and Native American. These variables are equal to one if the individual reports that they belong to the respective race group. A similar variables were defined for Hispanics, Puerto Ricans, Cubans, Mexicans, gender (one if male) and marriage (one if married). Since there are a number of missing values for marital status a second variable was defined equal to one if the marital status data are missing with the missing data on marital status recoded to zero.

\section{$\underline{3.5 \text { Consumer Price Index }}$}

The alcohol price and income are defined in real terms using a price index that reflects both county level prices for each year and national level prices over time. Since drug prices are state level, they are adjusted only with the national level price index. ${ }^{9}$ The county price index comes from the ACCRA. The ACCRA reports a cost of living index for over 250 cities and towns in the US. The ACCRA cost of living index is based on over sixty categories of consumer purchases and uses expenditure weights based on government survey data of expenditures of midmanagement households. The ACCRA cost of living index has no time variation. The national level CPI comes from the US Department of Commerce and uses 1982-1984 as the base year

\section{Regression Results}

Tables $2,3,4$ and 5 present the estimation results for alcohol, marijuana, cocaine, and heroin participation, respectively. The alcohol models are estimated with OLS and the drug

\footnotetext{
${ }^{9}$ A state level CPI could be computed but it would introduce measurement error due to matching individuals living in different size communities in a state with the same CPI. Rather than introduce this measurement error a state level adjustment is omitted.
} 
participation models are estimated as dichotomous probits. ${ }^{10}$ Each of these four tables presents the results for eight demographic groups. The demographic groups are: 1) the full sample, 2) White-male-non-Hispanics, 3) Blacks, 4) Native Americans, 5) Asians, 6) Hispanic, 7) Women, and 8) Youth. All regressions include price (or decriminalization for marijuana), income, marital status and time dummies. Other demographic variables are included when appropriate. Tables 2 through 5 also include, by demographic group, the number of observations, the price elasticity, and the weighted average participation. ${ }^{11}$ Table 2 and table 3 also include a weighted average measure of use by demographic group. Table 6 presents the results from 96 additional regressions. The 96 regressions resulted from the reestimation of each of the regressions in Tables 2 through 5, three additional times, with one additional price added. ${ }^{12}$ The purpose of these regressions is to search for evidence of complimentary, substitutability or independence of alcohol and drugs. Since there are 96 additional two price specifications, only the cross price effects from these specifications are presented in Table 6.

Table 2 presents the alcohol results for the eight demographic groups listed above. Participation and use are lower than in the full sample for Blacks, Native Americans, Asians, Hispanics, Women and Youth. For Native Americans that participate, use is higher than the full sample. Both participation and use are higher than the full sample for White-Male-non-Hispanics The regression coefficients are negative and significant for Black, Asian, Hispanic and Youth.

\footnotetext{
${ }^{10}$ There is data on the number of days that marijuana was used in the past month. This data is not appropriate to use with OLS since it is 95.5 percent zeros. The alternative data is dichotomous annual use. This data is appropriate to use with probit estimation.

${ }^{11}$ The alcohol elasticities are defined as the percentage change in number of days used with respect to a percentage change in the price. The cocaine and heroin elasticities are percentage change in the probability of participation with respect to a percentage change in price. The cocaine and heroin price elasticities were estimated by multiplying the normal density function of the estimated equation by the price variable coefficient and then by the ratio of the mean price to mean participation. The unweighted means were used in these computations rather than the weighted means which are reported in table 1 . The unweighted means were used since the estimated regression coefficients are based on unweighted data.

${ }^{12}$ The inclusion of an additional price variable increases colinearity problems. Each of the regressions in tables 2 through 5 were also reestimated with three additional prices added. While the results from this exercise are similar to those presented in Table 6 , the colinearity introduced by three additional price variables makes this approach more questionable than the inclusion of just a single additional price variable.
} 
Gender is positive and significant indicating that Women consume less. Marital status is negative indicating that married people consume less. The Native American variable is always insignificant. The Puerto Rican and Mexican variables are positive indicating that these groups consume more than other Hispanics. The price variable is negative and significant for the full sample, White-Male-non-Hispanics, Blacks and Women. Price is insignificant for Native Americans, Asians, and Youth and positive and significant for Hispanics. The own participation price elasticities were estimated for the four negative and significant price coefficients. The price elasticity did not vary significantly across the four demographic groups. The effects of income on alcohol is also very consistent across demographic groups. Income has a positive and significant effect on use for all groups except Blacks.

Table 3 presents the marijuana results for the eight demographic groups. Participation and use are lower than in the full sample for Native Americans, Asians, Hispanics and Women. Blacks have about the same participation and use as the full sample and WhiteMale-non-Hispanics have higher participation and use than the full sample Youth have higher participation but lower use than the full sample. The regression coefficients are negative and significant for Blacks, Asians and Hispanics. Gender is positive and significant indicating that Women consume less. Marital status is negative indicating that married people consume less. The Native American variable is insignificant three of four times. The Youth variable is mixed. The Puerto Rican and Mexican variables are positive indicating that these groups consume more than other Hispanics. The decriminalization variable is positive and significant in seven out of eight specifications. The only exception was for Native Americans. The effect of the decriminalization variable was estimated by calculating the difference between the value of the distribution function using all the coefficients and mean values and the value of the distribution function with the decriminalization variable set to zero. The magnitude of decriminalization effect 
across demographic groups was somewhat lower for Blacks than the full sample and higher for Asians than the full sample. The effects of income on marijuana participation varies considerably by demographic group. Income has a positive effect on participation for Youth and Hispanics, a negative effect on participation for White-Male-non-Hispanics and Blacks, and no effect on participation for Native Americans, Asians and Women and for the full sample

Table 4 presents the cocaine results for the eight demographic groups. Participation is lower than in the full sample for Asians and Women. Participation is higher than the full sample for White-Male-non-Hispanics, Native Americans, Hispanics and Youth. Blacks have about the same participation as in the full sample. The regression coefficients are negative and significant for Black, Asian, Hispanic and Youth. Gender is positive and significant indicating that Women consume less. Marital status is negative indicating that married people consume less. The Native American variable is insignificant three out of four times. The Puerto Rican and Mexican variables are positive indicating that these groups consume more than other Hispanics. The price variable is negative and significant in six out of eight specifications. The exceptions are for Blacks and Asians. The own price elasticities were estimated for the significant variables and do not differ significantly, with the exception of Native Americans who have a much more elastic demand. The effects of income on cocaine participation varies considerably by demographic group. Income has a positive effect on participation for Youth and Native Americans, a negative effect on participation for Blacks, and no effect on participation for the remaining groups.

Table 5 presents the heroin results for the eight demographic groups. Participation is lower than in the full sample for Women. Participation is higher than the full sample for Blacks, Native Americans, Hispanics and Youth., Native Americans, Hispanics and Youth. White-Malenon-Hispanics and Asians have about the same participation as in the full sample. The regression coefficients are generally insignificant for all race and ethnic categories. Gender is positive and 
significant indicating that Women consume less. Marital status is negative indicating that married people consume less. The price variable is negative and significant in three out of eight specifications. The three groups are the full sample, White-Male-non-Hispanics, and Women. The own price elasticities were estimated for the significant variables. The magnitude of the price effect were significantly larger for White-Male non-Hispanics than for the full sample or Women. Income has a significant negative effect on participation only for the full sample and for Women and was insignificant for all other groups.

Table 6 presents only the cross price effects from 96 additional regressions. Each of the 32 regressions in tables 2 through 5 were reestimated three times with the addition of one other drug price added to the specification. ${ }^{13}$ The results for each demographic group are presented in each column as in the other regression tables. The table contains a panel for each of the six drug pairs. Most of the coefficients which indicate that there is a relationship between the drug pairs are in the first three columns. These columns are for the full sample, White-Male-non-Hispanics and Blacks. These three groups may have more significant cross price effects than the other groups because these groups are both large samples and contain larger percentages of users Table six suggests complimentary of alcohol and marijuana, complimentary of alcohol and cocaine, complimentary of alcohol and heroin, and complimentary of cocaine and marijuana. The relationship between alcohol and marijuana shows that marijuana use is responsive to alcohol prices but that decriminalization has no effect on alcohol use.

\section{Conclusions}

Some consistent and inconsistent patterns emerge across drug categories. The demographic use patterns for alcohol and marijuana are similar, while cocaine and heroin each have distinct demographic patterns. For alcohol and marijuana, the evidence shows that all 
included groups consume less of these substances, except for White-Male-non-Hispanics who consume more. For Native Americans and youth the pattern of participation and use differ. For Native Americans that consume alcohol, their consumption is higher than the full sample. Marijuana participation for youth is higher than in the full sample, but for those who participate their use is lower than the full sample. For cocaine, Women and Asians consume less but the other included demographic groups consume more than average. For heroin, the simple means show that Blacks, Native Americans, Hispanic and Youth consume more than average. However, when other things are held constant these groups consume the same amount as the relevant omitted demographic categories.

The results also show a generally consistent pattern of negative price effects for all drugs and all demographic groups. The own price elasticities are similar by demographic category. This suggests that price oriented policies have a similar effect on each of the included demographic groups. The results also provide evidence that alcohol and illicit drugs are compliments. This suggests that policies which increase alcohol prices also reduce drug abuse. Similarly policies which increase drug prices reduce alcohol abuse.

\footnotetext{
${ }^{13}$ Only the cross price effects are presented in table 6 since the full set of results would require 15 additional tables.
} 


\section{$\underline{\text { References }}$}

Brown, G., and L.P. Silverman, "The Retail Price of Heroin: Estimation and Applications," in Quantitative Explorations in Drug Abuse Policy, I. Leveson editor, New York: Spectrum Publications, 1980 .

Chaloupka, F. and A. Laixuthai, "Do Youths Substitute Alcohol and Marijuana? Some Econometric Evidence", National Bureau of Economic Research Working Paper no. 4662, 1994.

DiNardo, J. and T. Lemieux, "Alcohol, Marijuana, and American Youth: The Unintended Effects of Government Regulation", Working Paper No. 4212, National Bureau of Economic Research, 1992.

DiNardo, J. "Law Enforcement the Price of Cocaine and Cocaine Use", Mathematical and Computer Modeling, vol. 17, no. 2, 1993.

Grossman, M., D. Coate, G. Arluck, "Price Sensitivity of Alcoholic Beverages in the United States: Youth Alcohol Consumption", in Control Issues in Alcohol Abuse Prevention: Strategies for States and Communities, ed. H. Holder, Greenwich, CT: JAI, 1987.

Heinen, D., and G. Pompelli, G. The Demand for Alcoholic Beverages: Economic and Demographic Effects", Southern Journal of Economics, no. 55, 1989

Johnston L., P. O'Malley, J. Bachman, Marijuana Decriminalization: The Impact on Youth 19751980, Ann Arbor, Michigan: Institute for Social Research, 1981.

Kendell, R.E., M. de Roumanie, and E. B. Ritson, "Effect of Economic Changes on Scottish Drinking Habits 1978-82", British Journal of Addiction, no. 78, 1983.

Kenkel, D., "Drinking, Driving, and Deterrence: The Effectiveness and Social Costs of Alternative Policies ", Journal of Law and Economics, vol. 36, October, 1993.

Leung, S. F. and C. Phelps, "My Kingdom for a Drink...?: A Review of Estimates of the Price Sensitivity of Demand for Alcoholic Beverages", in Economics and the Prevention of AlcoholRelated Problems, National Institute on Alcohol Abuse and Alcoholism, Washington DC, 1993

Model, K., "Crime Violence and Drug Policy", unpublished paper, Harvard University, 1992.

Model, K., "The Effect of Marijuana Decriminalization on Hospital Emergency Room Drug Episodes: 1975-1978", Journal of the American Statistical Association, vol. 88, no. 423, 1993

Nisbet, C. and F. Vakil, "Some Estimates of Price and Expenditure Elasticities of Demand for Marijuana Among UCLA Students", Review of Economics and Statistics, vol. 54, 1972

National Institute on Alcohol Abuse and Alcoholism, Eighth Special report to the US Congress on Alcohol and Health, US Department of Health and Human Services, Washington, DC, 1993

Pacula R., "Can Increasing the Beer Tax Reduce Marijuana Consumption?", unpublished paper, 
Duke University, Department of Economics, 1994.

Saffer, H. and F. Chaloupka, "The Demand for Illicit Drugs", National Bureau of Economic Research Working Paper No. 5238, Cambridge, 1995.

Silverman, L.P., and N.L. Spruill, "Urban Crime and the Price of Heroin," Journal of Urban Economics, 1977.

Sickles, R. and P. Taubman, "Who Uses Illegal Drugs?" AEA Papers and Proceedings, vol. 81, no. 2, May 1991.

Thies, C., and C. Register, "Decriminalization of Marijuana and the Demand for Alcohol, Marijuana and Cocaine", The Social Science Journal, vol. 30, no. 4, 1993.

US Department of Commerce, Bureau of the Census, City and County Databook, Washington DC, US Government Printing Office, 1993.

van Ours, J., "The Price Elasticity of Hard Drugs: The Case of Opium in the Dutch East Indies, 1923-1938", Journal of Political Economics, vol. 103, no. 2., 1995. 
Table 1

Weighted Average Means

from the National Household Surveys of Drug Abuse

\begin{tabular}{|c|c|}
\hline Variable & Definition and Mean \\
\hline Alcohol Use & $\begin{array}{l}\text { The number of days alcohol was used in the past } 31 \text { days, } \\
\mathrm{m}=3.49 \text {. }\end{array}$ \\
\hline $\begin{array}{l}\text { Marijuana } \\
\text { Participation }\end{array}$ & $\begin{array}{l}\text { Dichotomous indicator equal to one if a respondent reports using } \\
\text { marijuana in the past year, } \mathrm{m}=071 \text {. }\end{array}$ \\
\hline $\begin{array}{l}\text { Cocaine } \\
\text { Participation }\end{array}$ & $\begin{array}{l}\text { Dichotomous indicator equal to one if a respondent reports using } \\
\text { cocaine in the past year, } \mathrm{m}=.019 \text {. }\end{array}$ \\
\hline $\begin{array}{l}\text { Heroin } \\
\text { Participation }\end{array}$ & $\begin{array}{l}\text { Dichotomous indicator equal to one if a respondent reports using heroin } \\
\text { in the past year, } m=.001 \text {. }\end{array}$ \\
\hline Alcohol Price & The price of a liter of pure alcohol in 1983 dollars, $m=\$ 24.78$. \\
\hline $\begin{array}{l}\text { Marijuana } \\
\text { Decriminalized }\end{array}$ & $\begin{array}{l}\text { A dichotomous indicator equal to one for states that have eliminated } \\
\text { incarceration as a penalty for most marijuana possession offenses, } \mathrm{m}= \\
.303 \text {. }\end{array}$ \\
\hline Cocaine Price & Price of one pure gram of cocaine in 1983 dollars, $m=\$ 111.47$. \\
\hline Heroin Price & Price of one pure milligram of heroin in 1983 dollars, $m=\$ 6.48$. \\
\hline Real Income & Total personal income in 1983 dollars, $\mathrm{m}=\$ 11,781$. \\
\hline Gender & A dichotomous variable equal to one for males, $\mathrm{m}=.479$. \\
\hline Marital Status & $\begin{array}{l}\text { A dichotomous variable equal to one if married, } \mathrm{m}=.569 . \mathrm{A} \\
\text { dichotomous variable equal to one if marital status was missing is also } \\
\text { included, } \mathrm{m}=.033 \text {. }\end{array}$ \\
\hline Youth & $\begin{array}{l}\text { A dichotomous variable equal to one if an individual is } 12 \text { to } 20 \text { years of } \\
\text { age, } m=.155\end{array}$ \\
\hline Asian & $\begin{array}{l}\text { A dichotomous variable equal to one if an individual self-reports that } \\
\text { they are Asian, } m=.019\end{array}$ \\
\hline Native American & $\begin{array}{l}\text { A dichotomous variable equal to one if an individual self-reports that } \\
\text { they are Native American, } \mathrm{m}=.024\end{array}$ \\
\hline Black & $\begin{array}{l}\text { A dichotomous variable equal to one if an individual self-reports that } \\
\text { they are Black, } m=.151 \text {. }\end{array}$ \\
\hline Hispanic & $\begin{array}{l}\text { A dichotomous variable equal to one if an individual self-reports that } \\
\text { they are Hispanic, } m=.078 \text {. }\end{array}$ \\
\hline Puerto Rican & $\begin{array}{l}\text { A dichotomous variable equal to one if an individual self-reports that } \\
\text { they are Puerto Rican, } m=.019\end{array}$ \\
\hline Mexican & $\begin{array}{l}\text { A dichotomous variable equal to one if an individual self-reports that } \\
\text { they are Mexican, } m=.084\end{array}$ \\
\hline Cuban & $\begin{array}{l}\text { A dichotomous variable equal to one if an individual self-reports that } \\
\text { they are Cuban, } m=.007\end{array}$ \\
\hline
\end{tabular}

* Final sample size when missing values were excluded is 49,802 . 


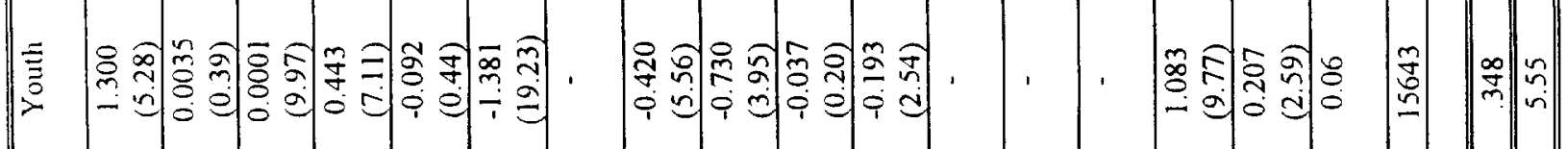

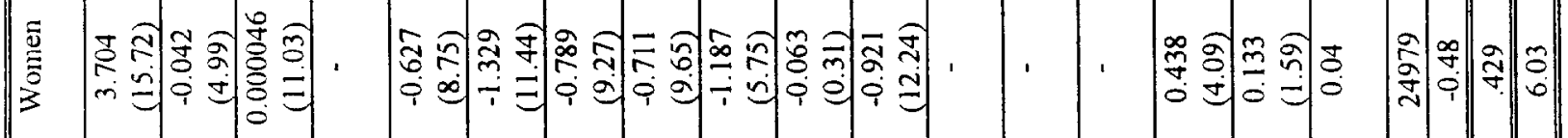

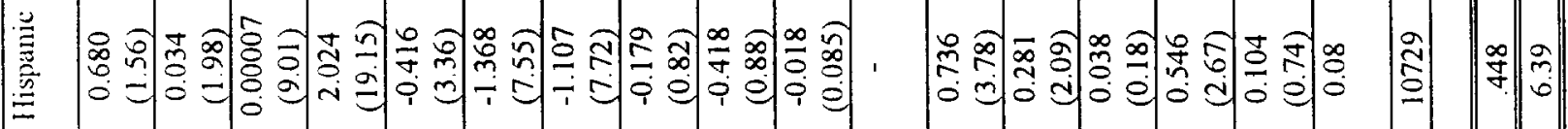

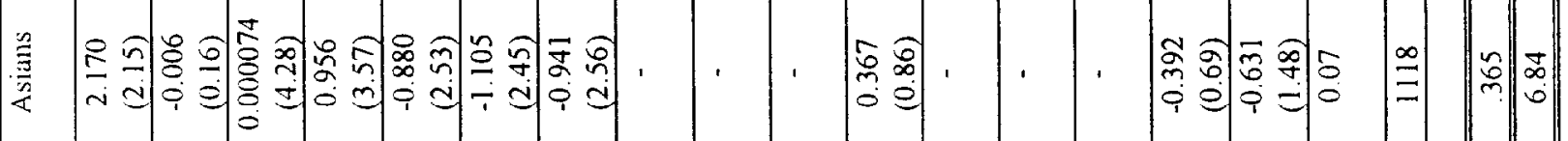

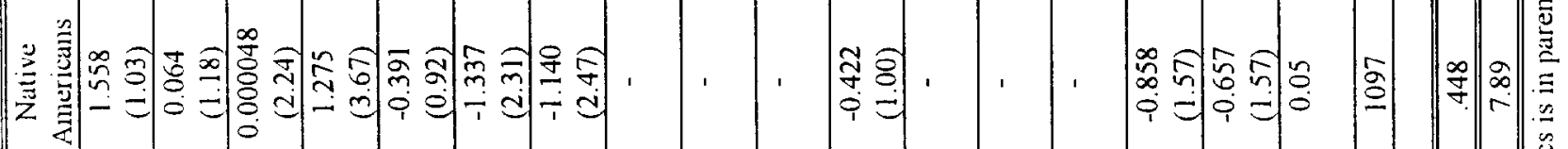

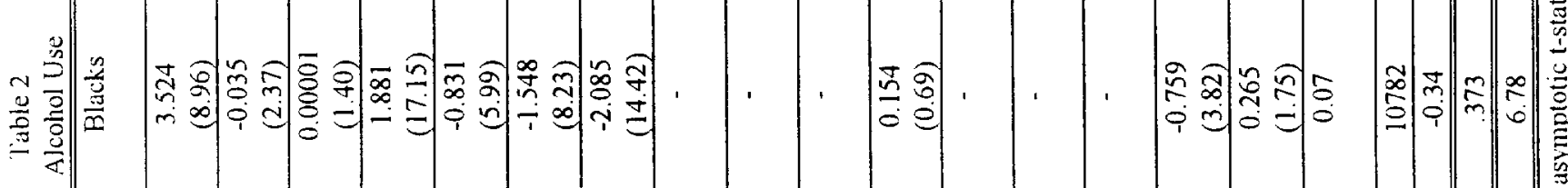

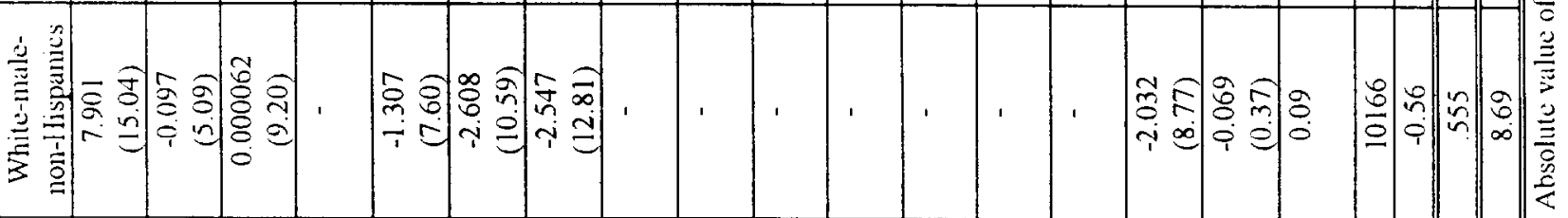

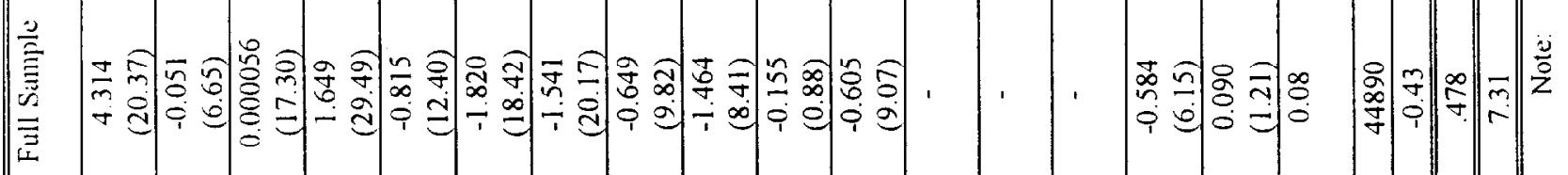

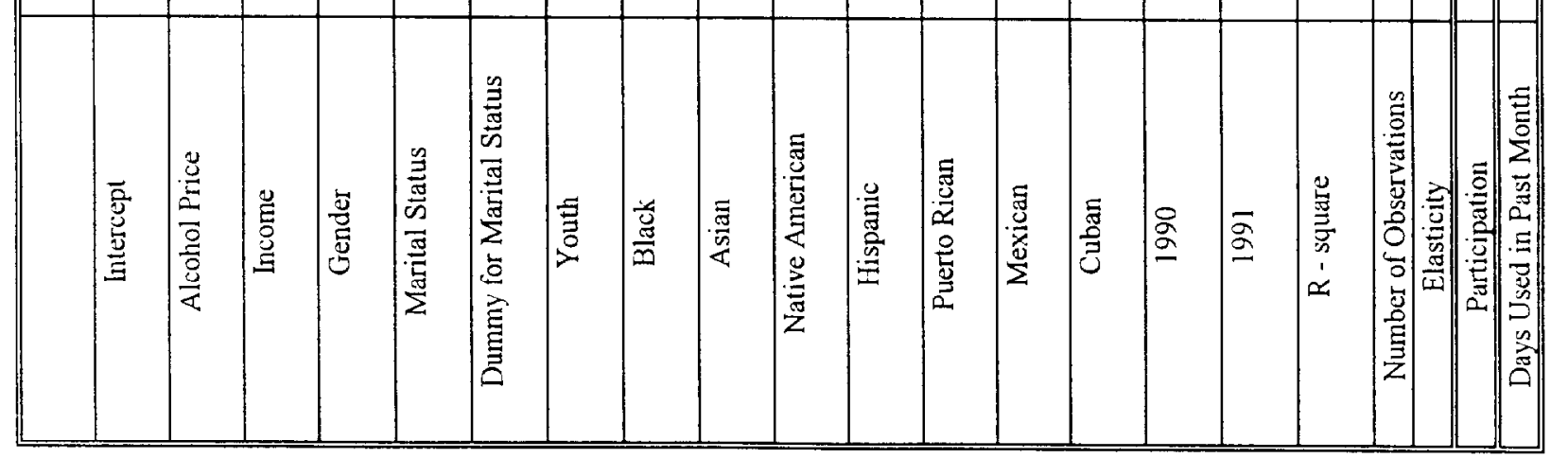




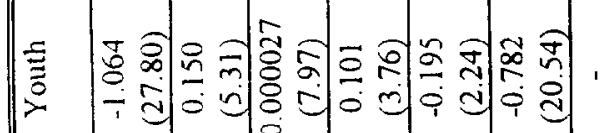

的国䜤

으응ㅇㅇㅇㅇㅇㅇ

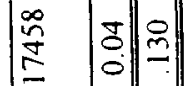

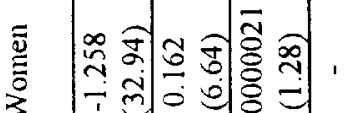

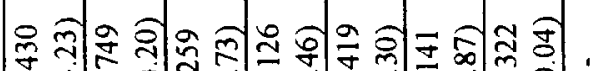

으의웡

药 2.

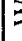

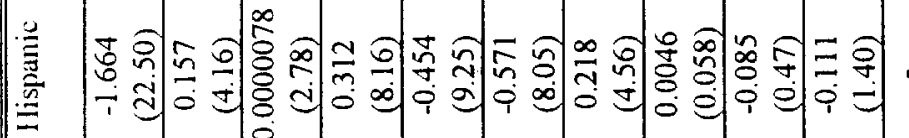

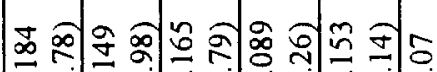

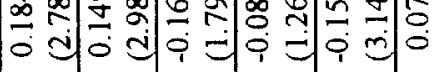

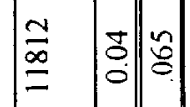

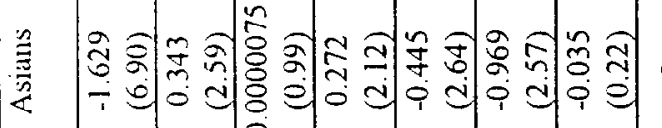

กิ

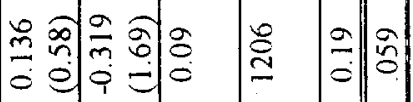

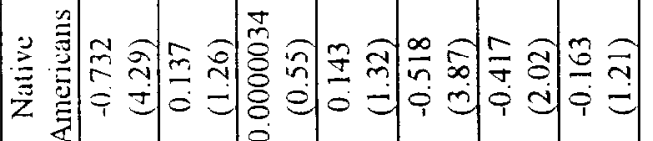

总各!

i

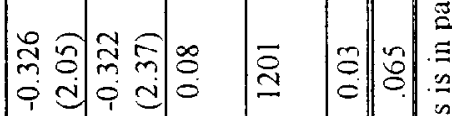

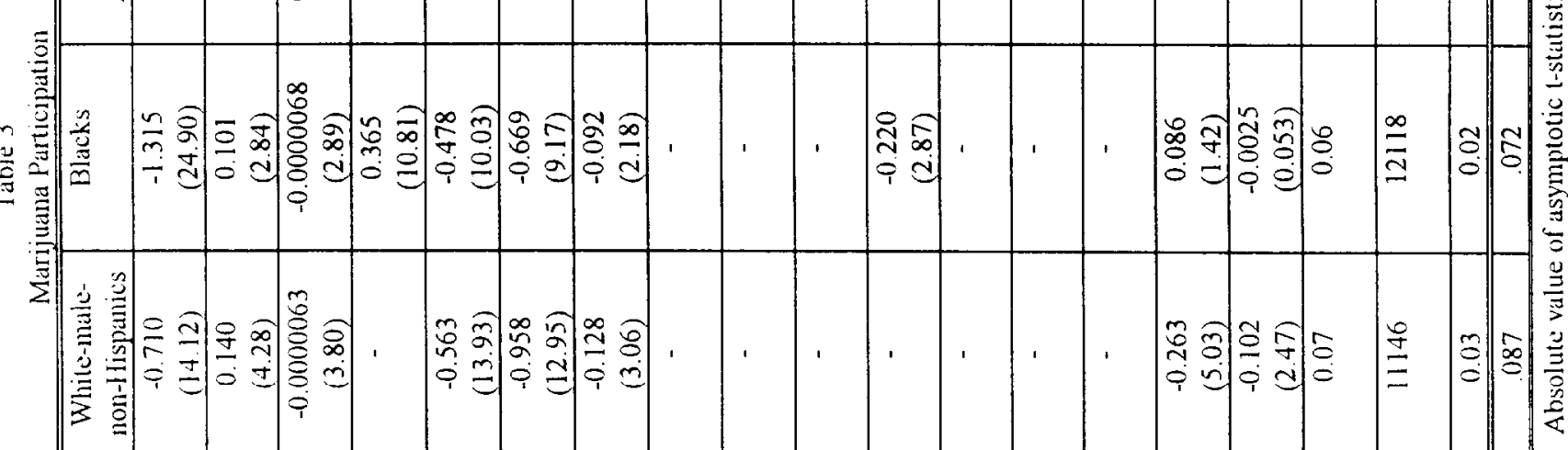

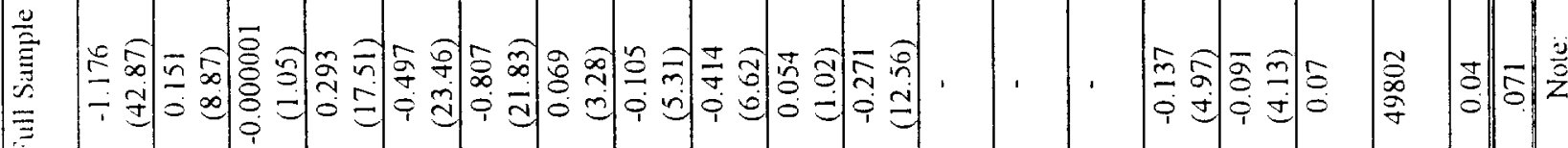

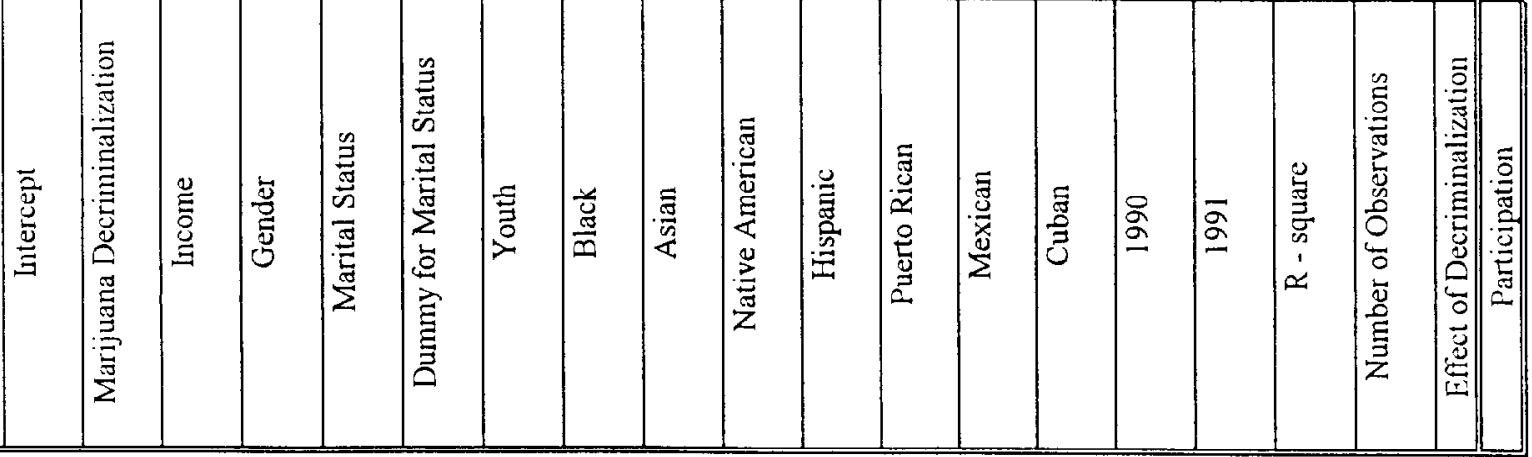




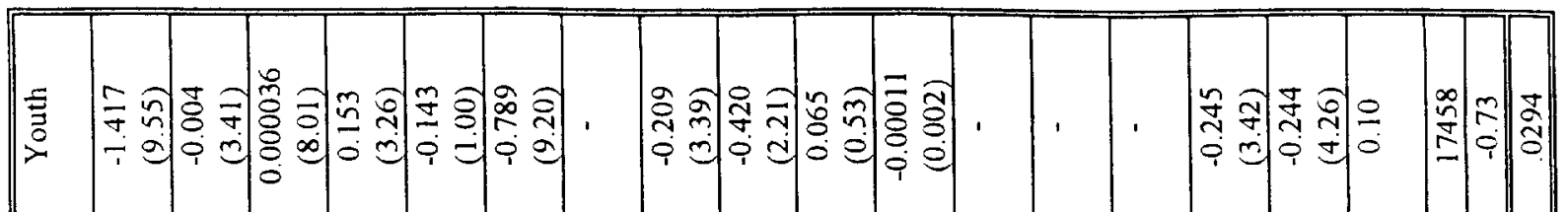

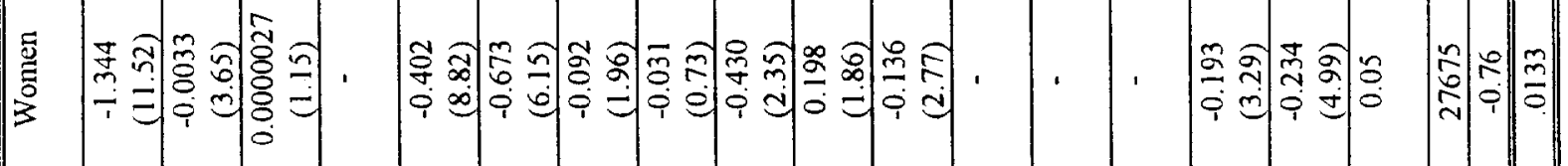

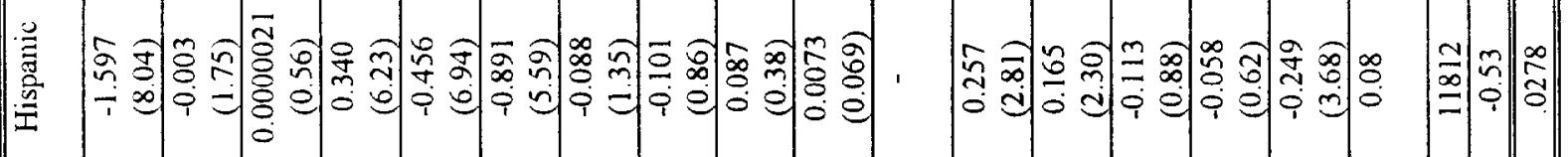

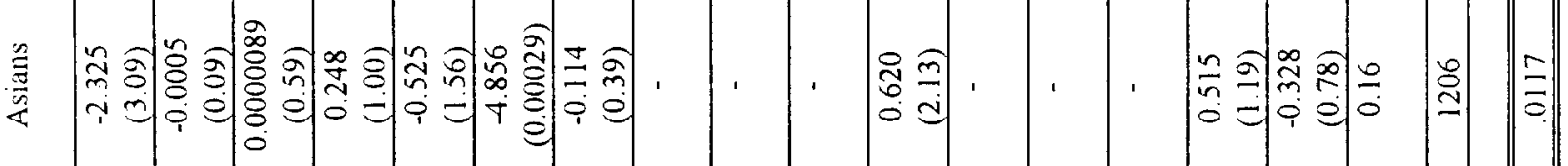

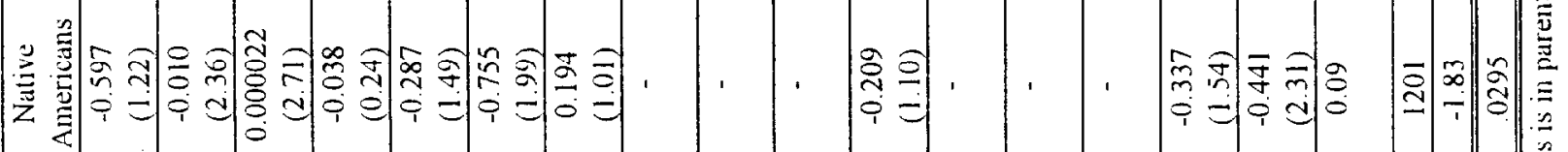

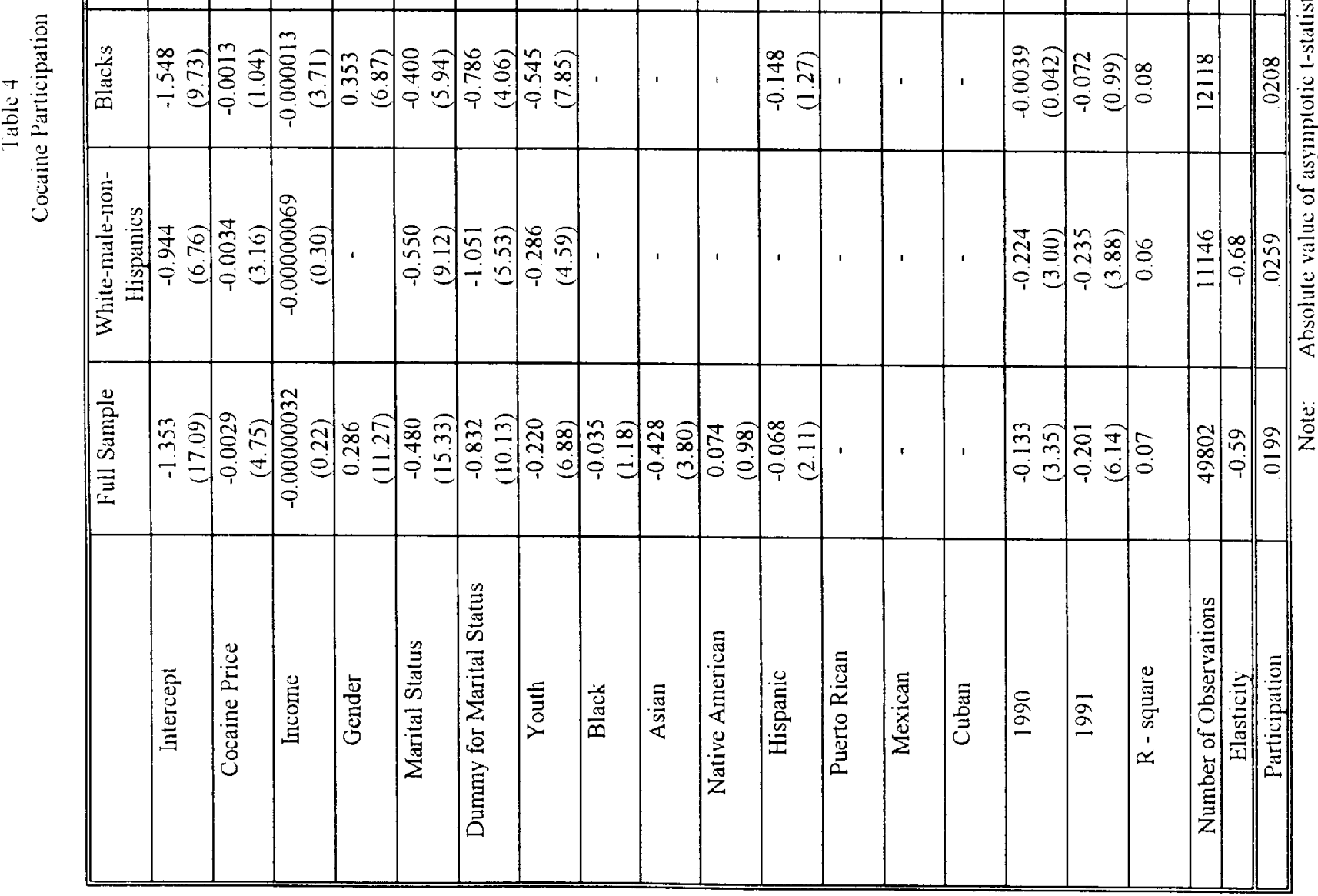




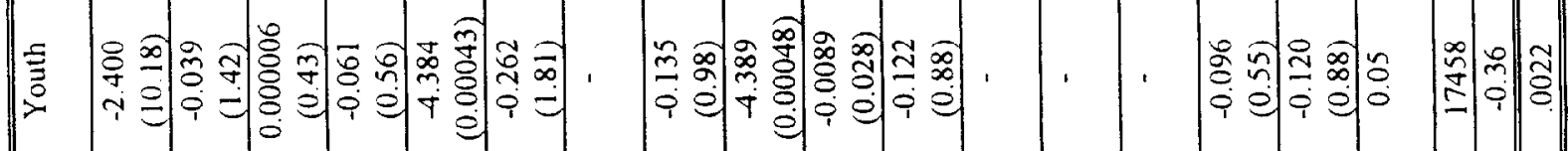

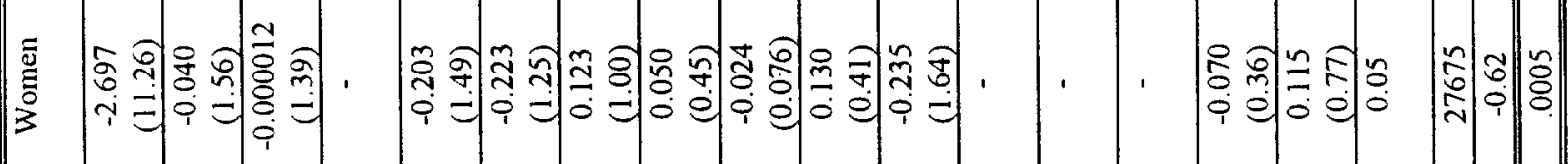

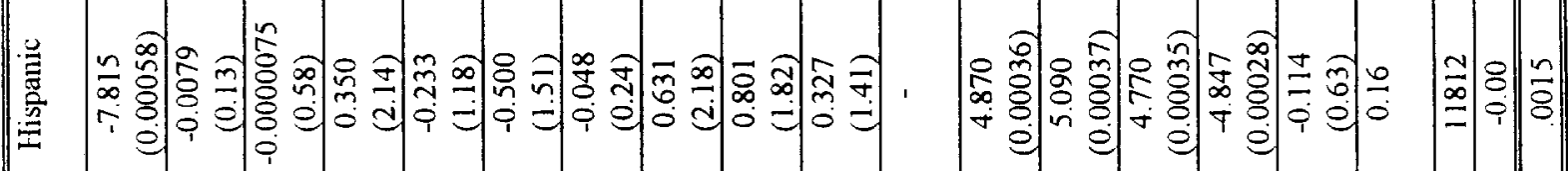

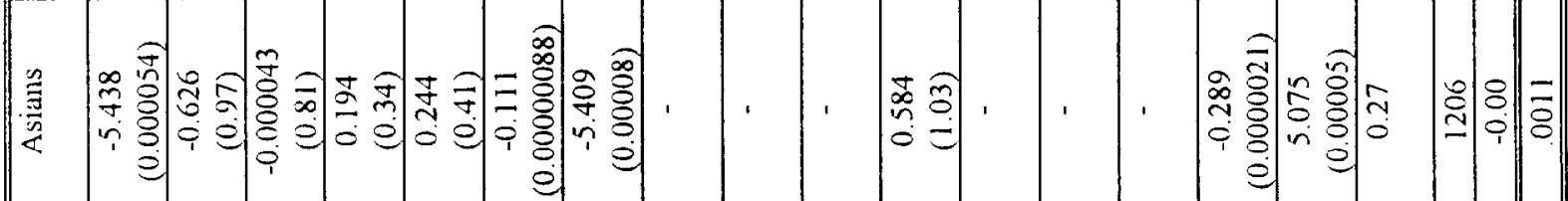

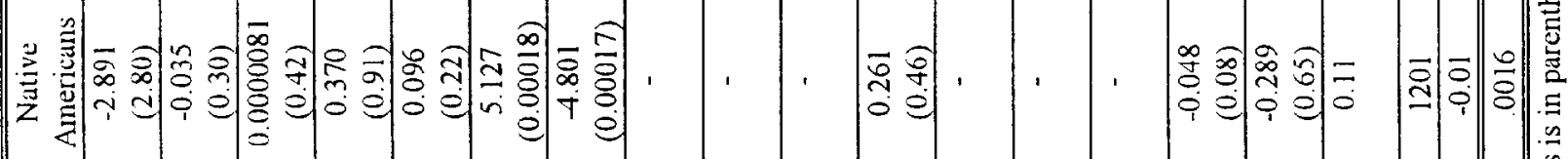

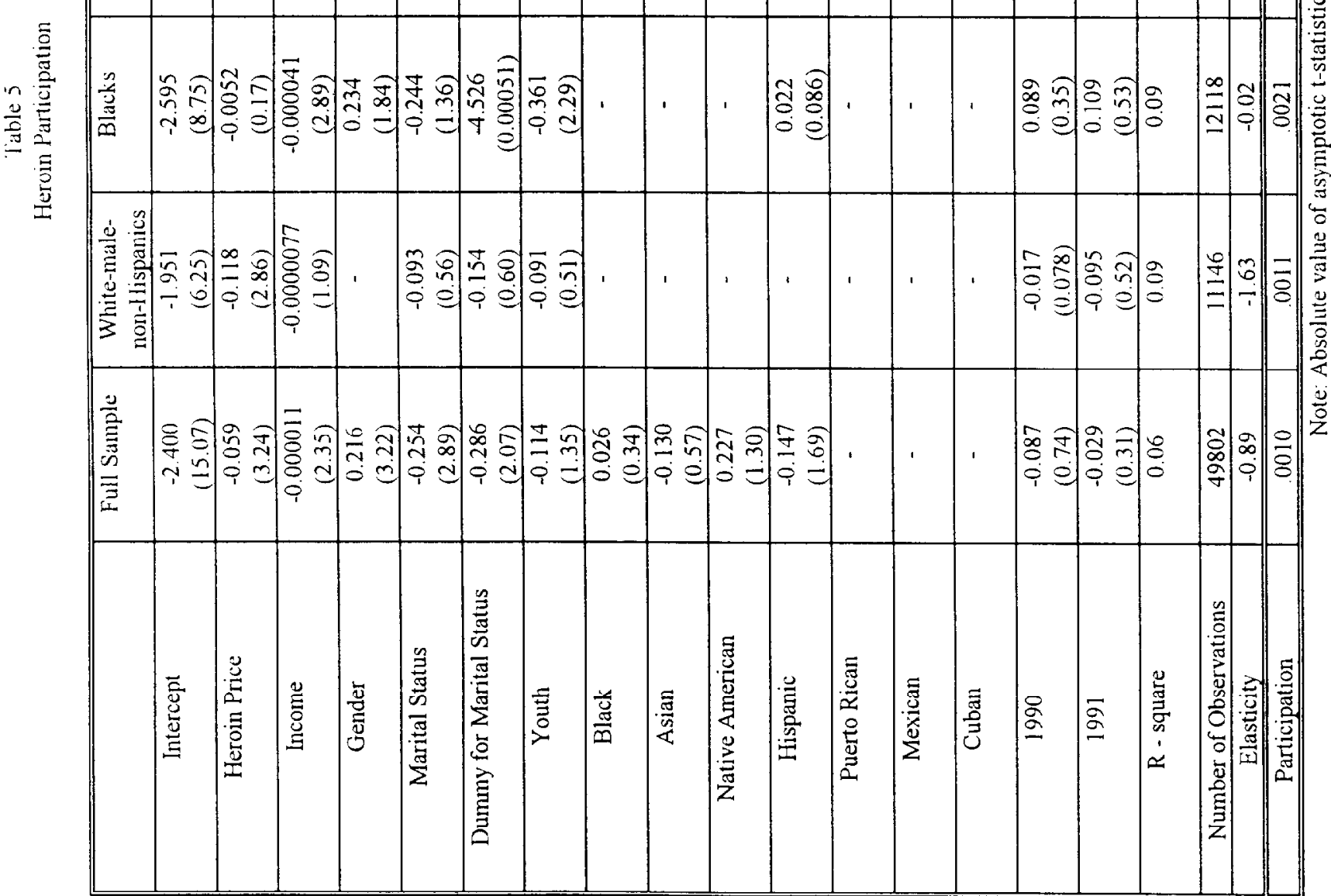




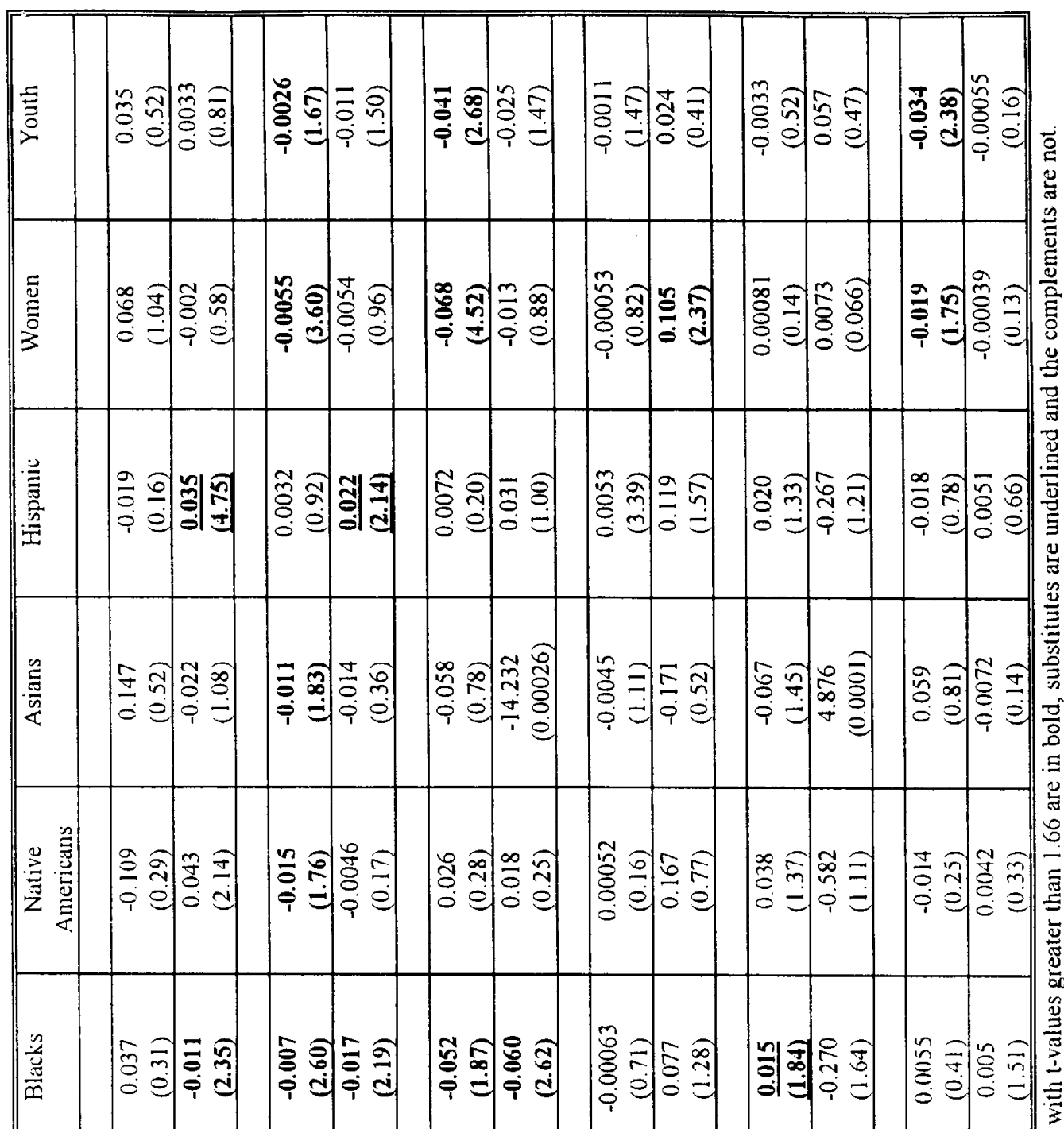

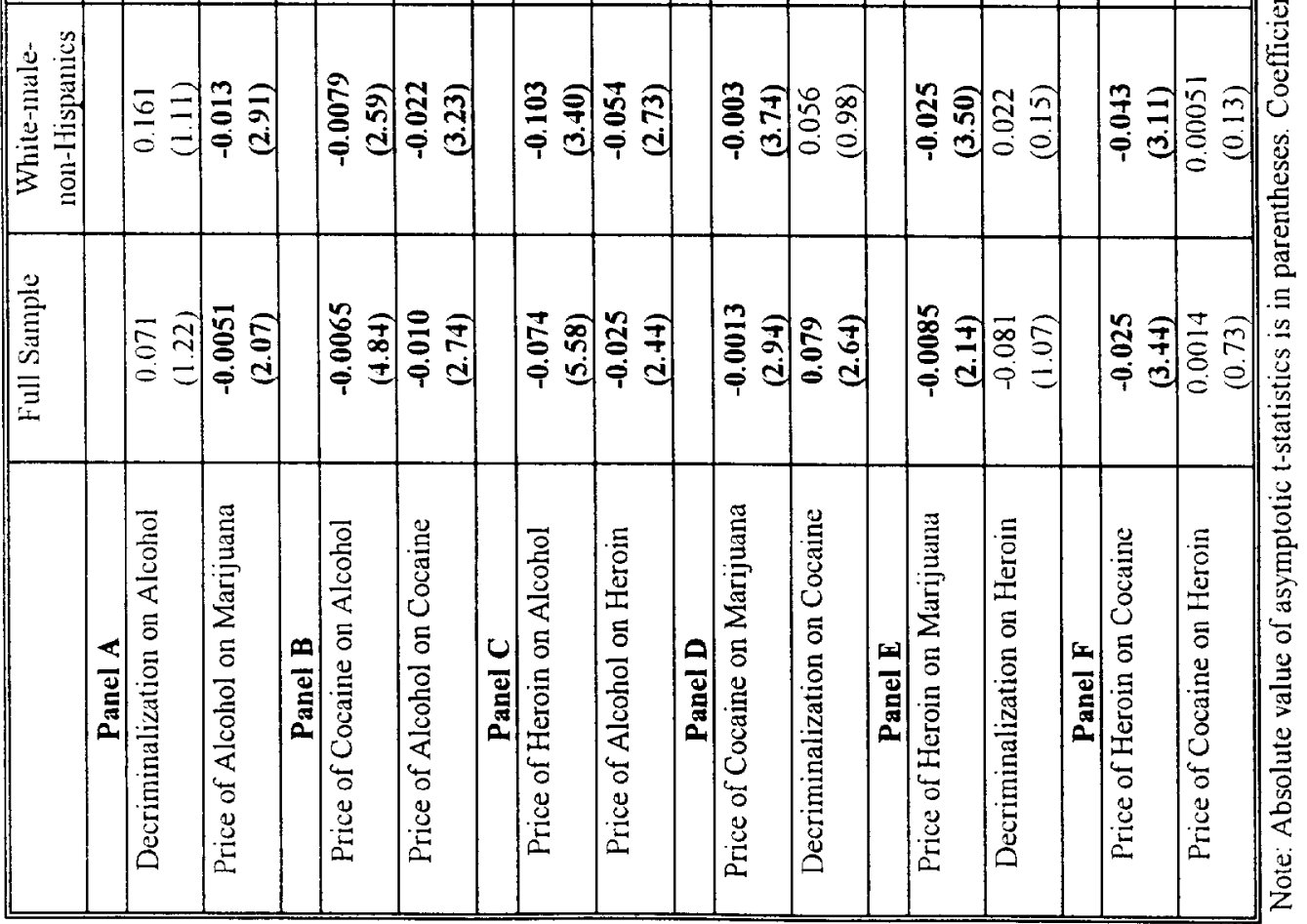

